\title{
Nutritional, hormonal, and depot-dependent regulation of the expression of the small GTPase Rab18 in rodent adipose tissue
}

\author{
Marina R Pulido ${ }^{1,2}$, Yoana Rabanal-Ruiz ${ }^{1,2}$, Farid Almabouada ${ }^{1,2}$, Alberto Díaz-Ruiz,2, \\ María A Burrell ${ }^{3}$, María J Vázquez ${ }^{2,4}$, Justo P Castaño ${ }^{1,2}$, Rhonda D Kineman ${ }^{5}$, \\ Raúl M Luque ${ }^{1,2}$, Carlos Diéguez ${ }^{2,4}$, Rafael Vázquez-Martínez ${ }^{1,2}$ and María M Malagón ${ }^{1,2}$ \\ ${ }^{1}$ Department of Cell Biology, Physiology and Immunology, Instituto Maimónides de Investigación Biomédica \\ de Córdoba (IMIBIC), University of Córdoba/Hospital Universitario Reina Sofia, Edificio Severo-Ochoa, PI. 3, \\ Campus Univ. de Rabanales, E-14014 Córdoba, Spain \\ ${ }^{2}$ CIBER Fisiopatología de la Obesidad y Nutrición (CIBERobn), Instituto de Salud Carlos III, Spain \\ ${ }^{3}$ Department of Histology and Pathology, University of Navarra, 31008 Pamplona, Spain \\ ${ }^{4}$ Department of Physiology, School of Medicine, Instituto de Investigaciones Sanitarias (IDIS), University of Santiago \\ de Compostela, 15782 Santiago de Compostela, Spain \\ ${ }^{5}$ Department of Medicine, University of Illinois at Chicago, Jesse Brown VA Medical Center, Chicago, \\ Illinois 60612, USA
}

\author{
Correspondence \\ should be addressed to \\ M M Malagón at \\ Email \\ bc1mapom@uco.es
}

\begin{abstract}
There is increasing evidence that proteins associated with lipid droplets (LDs) play a key role in the coordination of lipid storage and mobilization in adipocytes. The small GTPase, RAB18, has been recently identified as a novel component of the protein coat of LDs and proposed to play a role in both $\beta$-adrenergic stimulation of lipolysis and insulin-induced lipogenesis in 3T3-L1 adipocytes. In order to better understand the role of Rab18 in the regulation of lipid metabolism in adipocytes, we evaluated the effects of age, fat location, metabolic status, and hormonal milieu on Rab18 expression in rodent white adipose tissue (WAT). Rab18 mRNA was undetectable at postnatal day 15 (P15), but reached adult levels by P45, in both male and female rats. In adult rats, Rab18 immunolocalized around LDs, as well as within the cytoplasm of mature adipocytes. A weak Rab18 signal was also detected in the stromal-vascular fraction of WAT. In mice, fasting significantly increased, though with a distinct time-course pattern, Rab18 mRNA and protein levels in visceral and subcutaneous WAT. The expression of Rab18 was also increased in visceral and subcutaneous WAT of obese mice (diet-induced, ob/ob, and New Zealand obese mice) compared with lean controls.

Rab18 expression in rats was unaltered by castration, adrenalectomy, or GH deficiency but was increased by hypophysectomy, as well as hypothyroidism. When viewed together, our results suggest the participation of Rab18 in the regulation of lipid processing in adipose tissue under both normal and pathological conditions.
\end{abstract}

\author{
Key Words \\ - fasting \\ - gene expression \\ - lipid metabolism \\ - obesity \\ - Rab18 \\ - white adipose tissue
}

http://www.jme.endocrinology-journals.org DOI: 10.1530/JME-12-0140
C 2013 Society for Endocrinology Printed in Great Britain
Published by Bioscientifica Ltd.
Journal of Molecular

Endocrinology

(2013) 50, 19-29 


\section{Introduction}

Adipose tissue has received much attention over the last two decades due to the discovery of its role as an active endocrine organ (Kershaw \& Flier 2004). Moreover, recent discoveries have also significantly changed the classical view of adipose tissue as an inert energy depot and unveiled the complex regulation of adipose tissue lipolysis and lipogenesis. Indeed, regulation of lipid metabolism in adipocytes depends on a fine balance between multiple factors, both extracellular and intracellular (Brasaemle 2007, Kolditz \& Langin 2010, Watt \& Spriet 2010). Although to date there exists a wealth of information on the extracellular factors that regulate adipocyte function, the intracellular components and mechanisms that participate, directly or indirectly, in the control of lipid trafficking and metabolism are less well known.

Lipid droplets (LDs) are responsible for the storage of excess energy in the form of neutral lipids and thus play a key role in adipocytes (Murphy 2001, Wolins et al. 2006). LDs are coated by proteins that are required for optimal lipid storage and fatty acid release (Brown 2001, Goodman 2008). LD coat proteins include lipid metabolic enzymes (Brasaemle et al. 2004, Kuerschner et al. 2008, Miyoshi et al. 2008, Guo et al. 2009), the PAT family of proteins (named after perilipin, adipophilin, and TIP47) that coordinate lipid storage and utilization (Brasaemle 2007, Ducharme \& Bickel 2008), the cell death-inducing DFF45-like effector (CIDE) family of proteins that regulate lipogenesis (Gong et al. 2009), and proteins regulating membrane trafficking events, which include RAB and ARF GTPases, soluble $N$-ethylmaleimide-sensitive factor activating protein receptor (SNARE) proteins, and motor proteins (Liu et al. 2007, Guo et al. 2008, Hommel et al. 2010). In particular, several members of the RAB family of small GTPases have been shown to decorate the surface of LDs (Brasaemle et al. 2004, Murphy et al. 2009), yet the precise function of most $\mathrm{RAB}$ proteins expressed in adipocytes remains unknown. Among those best documented is RAB18, which was first shown to associate with the surface of LDs in 3T3-L1 adipocytes in response to $\beta$-adrenergic stimulation and was therefore proposed to be involved in the release of lipids from LDs (Brasaemle et al. 2004, Martin et al. 2005, Ozeki et al. 2005). Consistent with these early studies, we recently demonstrated that RAB18 overexpression increased basal lipolysis and RAB18 silencing-impaired forskolin-stimulated lipolysis in 3T3-L1 cells (Pulido et al. 2011). Intriguingly, we also observed that insulin, like the $\beta$-adrenergic receptor agonist isoproterenol, induced the recruitment of RAB18 to the surface of LDs in 3T3-L1 cells, where silencing of RAB18 impaired insulin-stimulated lipogenesis and its overexpression enhanced lipogenesis (Pulido et al. 2011). Together, these data suggest that RAB18 plays a role in both lipolysis and lipogenesis in 3T3-L1 adipocytes. In order to better understand the role of RAB18 in the regulation of lipid metabolism in primary adipocytes, in the current study, we evaluated the effects of age, fat location, metabolic status, and hormonal milieu on RAB18 expression (mRNA and protein) in rodent white adipose tissue (WAT).

\section{Materials and methods}

\section{Reagents}

Rabbit anti-rat RAB18 was purchased from Calbiochem (Barcelona, Spain). Anti-mouse adiponectin was from Chemicon Int. (Temecula, CA, USA) and rabbit antihuman CD45 was from Santa Cruz Biotechnology. TRIzol Reagent and DMEM were from Invitrogen Corp., PowerScriptTM reverse transcriptase from Clontech, SYBR Green-tag DNA polimerase from Bio-Rad, dNTPs from Ecogen (Madrid, Spain), and random primers from GE Healthcare (Buckinghamshire, UK). Normal goat serum and Envision Method Kit were from Dako (Glostrup, Denmark), ECL Plus Detection System from GE Healthcare, and anti-rabbit Alexa488-conjugated secondary antibody from Invitrogen Corp. Unless otherwise indicated, all other reagents were purchased from Sigma-Aldrich.

\section{Animal studies}

Sprague Dawley rats and GH-deficient dwarf and wild-type Lewis rats were obtained from Harlan Iberica (Barcelona, Spain). C57BL/6J, ob/ob mice and their lean littermate controls, as well as New Zealand obese (NZO) mice and their controls, were obtained from Jackson Laboratories (Bar Harbor, ME, USA). Experimental procedures were approved by the Institutional Animal Care and Use Committee. Animals had free access to standard rodent chow and tap water unless otherwise specified. Post mortem, subcutaneous (obtained from the inguinal fat pad), and visceral (obtained from the peri-gonadal fat pad) WAT samples were either processed for immunohistochemistry and/or frozen in liquid nitrogen and stored at $-80^{\circ} \mathrm{C}$ until analysis of Rab18 mRNA levels by RT-PCR or RAB18 protein content by immunoblotting, as described below.

Published by Bioscientifica Ltd. 
Ad libitum-fed Sprague Dawley rats $~$ At postnatal (P) day $15,45,60$, or 90, male and female rats were killed under fed conditions and WAT samples were excised and processed for immunohistochemistry or frozen for protein or mRNA analysis, as described below. In addition, in order to investigate the presence of RAB18 in the two components of adipose tissue, mature adipocytes and the stromal-vascular fraction (SVF; Frayn et al. 2003) were freshly isolated from WAT of P90 male Sprague Dawley rats, as described previously (Peinado et al. 2010). After separation, the two fractions were frozen in liquid nitrogen and stored at $-80{ }^{\circ} \mathrm{C}$ for analysis of Rab18 mRNA or protein content or freshly isolated mature adipocytes were processed for immunohistochemistry, as described below.

Fasted mice - Visceral and subcutaneous WAT was collected from 10-week-old, C57bl/6J mice under ad libitum-fed conditions or after a 12-h fast (food removed at $1900 \mathrm{~h}$ ) or 24 and $48 \mathrm{~h}$ (food removed at $0700 \mathrm{~h}$ ). Samples were stored at $-80{ }^{\circ} \mathrm{C}$ until analysis of RAB18 mRNA and protein.

Diet-induced and genetically obese mice $\bullet$ WAT was collected from $\mathrm{C} 57 \mathrm{Bl} / 6 \mathrm{~J}$ mice maintained on a high-fat (fat $=60 \mathrm{kcal} \%$, carbohydrate $=20 \mathrm{kcal} \%$, protein $=20 \mathrm{kcal} \%$; D12492, Research Diets, Brunswick, NJ, USA) or a low-fat diet (fat $=10 \mathrm{kcal} \%$, carbohydrate $=70 \mathrm{kcal} \%$, protein $=20 \mathrm{kcal} \%$; D12450B, Research Diets) for 10 or 16 weeks (diet starting at 4 weeks of age), as previously reported (Luque \& Kineman 2006). In addition, WAT samples from a model of monogenic obesity, $o b / o b$ mice (10 weeks of age), or from a model of polygenic obesity, NZO mice (10 weeks of age), were also examined. We also analyzed the effect of 48-h fasting in NZO mice. Samples were stored at $-80^{\circ} \mathrm{C}$ until analysis of $\mathrm{Rab} 18 \mathrm{mRNA}$ and protein.

Hypophysectomized rats $~$ Male Sprague Dawley rats were either sham-operated or hypophysectomized and WAT was collected 4 weeks after surgery as described previously (Barreiro et al. 2002).

Growth hormone deficient dwarf rats $~$ WAT was collected from 7-week-old controls and GH-deficient Lewis male rats, commonly referred to as spontaneous dwarf (SDR). In these rats, circulating GH levels are undetectable, due to a spontaneous point mutation in the GH gene resulting in a premature stop codon (Charlton et al. 1988).

Gonadectomized rats - At P21, male and female Sprague Dawley rats were sham-operated or gonadectomized and killed 24 days post-surgery and WAT samples collected, as previously reported (Nogueiras et al. 2003).

Adrenalectomized rats $~$ Sprague Dawley rats were either sham-operated or bilaterally adrenalectomized, as previously reported (Barreiro et al. 2002). Both shamoperated and adrenalectomized rats received a daily s.c. administration of $40 \mu \mathrm{g}$ dexamethasone dissolved in $200 \mu \mathrm{l}$ saline or $200 \mu \mathrm{l}$ saline alone for 8 days. Thereafter, sampling of WAT was carried out.

Hypo- and hyper-thyroid rats - Hypothyroidism was induced in male Sprague Dawley rats by adding $0.1 \% 3$-amino-1,2,4-triazole to the drinking water, and hyperthyroidism was induced by chronic s.c. administration of $100 \mu \mathrm{g} /$ day L-thyroxine sodium salt pentahydrate, as previously reported (Lopez et al. 2001). The efficiency of the treatments was confirmed by evaluating the circulating levels of $\mathrm{T}_{4}$ and $\mathrm{T}_{3}$. Data from L-thyroxine-treated animals has been recently published (Varela et al. 2012). Administration of amino-triazole significantly decreased plasma levels of both $\mathrm{T}_{4}(107 \pm 9$ vs $56 \pm 7 \mathrm{nmol} / \mathrm{l}$ in control animals and treated animals respectively; $P<0.01)$ and $\mathrm{T}_{3}(1.63 \pm 0.1$ vs $0.56 \pm 0.09 \mathrm{nmol} / 1$ in control animals and treated animals respectively; $P<0.001)$.

\section{Immunohistochemistry}

Immunohistochemical detection of Rab18 was carried out in paraffin-embedded sections of visceral fat from adult (P90) male Sprague Dawley rats, which were processed as described previously (Archanco et al. 2007). Briefly, tissue sections were pre-incubated ( $1 \mathrm{~h}$ at room temperature) with 1:20 normal goat serum in $0.05 \mathrm{M}$ Tris- $\mathrm{HCl}$ buffer, $0.5 \mathrm{M} \mathrm{NaCl}$, pH 7.6 (TBS), and exposed overnight $\left(4{ }^{\circ} \mathrm{C}\right)$ to anti-rat RAB18 antibody (1:500). The signal was detected using the Envision Method Kit consisting of a goat anti-rabbit IgG secondary antibody coupled to a peroxidase-labeled dextran polymer. Peroxidase activity was revealed using $0.03 \%$ 3,3-diaminobenzidine. The reaction was stopped by a wash with TBS. Finally, sections were dehydrated and mounted with a mixture of distyrene, a plasticizer, and xylene (DPX). Negative control slides without primary antibody were included to assess nonspecific staining.

Immunohistochemical detection of Rab18 was also performed in freshly isolated mature adipocytes fixed with $4 \%$ paraformaldehyde (15 min) and then incubated with PBS containing $0.1 \%$ saponin and $1 \%$

Published by Bioscientifica Ltd. 
BSA ( $1 \mathrm{~h}$ at RT). Cells were exposed overnight to anti-rat RAB18 antibody (1:500), followed by a 2-h incubation with anti-rabbit Alexa594-conjugated secondary antibody (1:500). The signal was visualized using a TCS-SP2AOBS confocal laser scanning microscope (Leica Corp., Heidelberg, Germany).

\section{Western blot analysis}

Samples of total adipose tissue, mature adipocytes, and SVF were disrupted in lysis buffer (20 mM Tris, $\mathrm{pH} 7.4$, $150 \mathrm{mM} \mathrm{NaCl}, 1 \%$ Triton, and protease inhibitors). Total protein $(150 \mu \mathrm{g} /$ lane) was loaded in $12.5 \%$ SDS-PAGE gels and transferred to nitrocellulose membranes. After Ponceau staining to ensure equal sample loading, membranes were blocked for $1 \mathrm{~h}$ with $5 \%$ dried milk in TTBS (TBS buffer with $0.05 \%$ Tween 20). Thereafter, membranes were incubated with primary antibodies (rabbit anti-rat RAB18, rabbit anti-mouse adiponectin, or rabbit anti-human CD45) overnight at $4{ }^{\circ} \mathrm{C}$, washed and incubated with peroxidase-conjugated secondary antibodies for $1 \mathrm{~h}$ at room temperature. Rabbit polyclonal anti- $\beta$-actin antibody was employed as a loading control. The signal was detected using the ECL Plus Detection System (GE Healthcare).

\section{Real-time RT-PCR}

Total RNA was isolated from WAT samples using TRIzol reagent. To assess RNA quality, the $260 \mathrm{~nm} / 280 \mathrm{~nm}$ absorbance ratio was measured and samples were only used when this ratio was $\sim 2$. RT reactions were carried out in a $20 \mu \mathrm{l}$ final volume by adding $2 \mu \mathrm{g}$ total RNA, $1 \mu \mathrm{l}$ PowerScript, $10 \mu \mathrm{M}$ dNTP mixture, and $250 \mathrm{ng}$ random hexamer primers. The reaction mixtures were incubated at $70{ }^{\circ} \mathrm{C}$ for $10 \mathrm{~min}$ and at $42^{\circ} \mathrm{C}$ for $1 \mathrm{~h}$ and then heated at $70{ }^{\circ} \mathrm{C}$ for $15 \mathrm{~min}$ and cooled on ice. Real-time RT-PCR was performed using SYBR Green tagging quantification in an iCycler IQ PCR detection System (Bio-Rad) according to the manufacturer's instructions. The specific primers used were 5'-CTCTGAAGATCCTCATCATTGG-3' sense and $5^{\prime}$-CTTTCTTGACCAGCTGTATCCCA-3' antisense for rat Rab18 and 5'-CTCTGAAGATACTCATCATCGG-3' sense and 5'-CCTCTCTTGACCAGCTGTATCCCA-3' antisense for mouse Rab18. Both primer pairs amplify $185 \mathrm{bp}$ fragments. As endogenous reference genes, the hypoxanthine phosphoribosyltransferase gene (Hprt) (for studies in rat adipose tissue) or the $18 \mathrm{~S}$ small subunit ribosomal RNA gene (for studies in mouse adipose tissue) were amplified in parallel to $R a b 18$ using the specific primers 5'-CAGTCCCAGCGTCGTGATTA-3' sense and 5'-CTCTGAAGATCCTCATCATTGG-3' antisense, which amplify a $139 \mathrm{bp}$ fragment of the rat Hprt gene, and 5'-CCCATTCGAACGTCTGCCCTAT-3' sense and 5'-TGCTGCCTTCCTTGGATGTGGTA-3' antisense, which amplify a $137 \mathrm{bp}$ fragment of the mouse $18 \mathrm{~S}$ rRNA gene. PCRs consisted of an initial activation and denaturing cycle at $95^{\circ} \mathrm{C}$ for $5 \mathrm{~min}$, followed by 35 cycles at $95^{\circ} \mathrm{C} / 30 \mathrm{~s}$, $60{ }^{\circ} \mathrm{C} / 30 \mathrm{~s}$, and $72{ }^{\circ} \mathrm{C} / 30 \mathrm{~s}$. The amount of PCR products formed in each cycle was estimated on the basis of SYBR Green I fluorescence dye. Controls consisting of reaction mixture without cDNA were negative in all runs. cDNAs were sequenced to ensure that the correct mRNA transcripts were quantified (Central Sequencing Service, University of Cordoba, Cordoba, Spain).

Calculation of relative expression levels of the different transcripts was performed based on the cycle threshold $\left(C_{\mathrm{T}}\right)$ method. Thus, the $C_{\mathrm{T}}$ value for each sample was calculated using the iCycler iQ real-time PCR detection system software with an automatic fluorescence threshold setting. Reactions were performed in triplicate. Standard curves were constructed for Rab18 and the housekeeping genes and amplification profiles were analyzed off-line using the iCycler IQ optical system software 3.1 (Bio-Rad).

\section{Statistical analysis}

The number of animals used in each experimental setting is indicated in the figures. In each experiment, all samples were processed at the same time in order to reduce interexperimental variability. Single comparisons were performed using Student's t-test. Multiple comparisons were assessed by one-way ANOVA followed by a Newman-Keuls test for parametric data or by Kruskal-Wallis followed by a Dunn's test for nonparametric data using GraphPad Prism 4 (La Jolla, CA, USA). Differences were considered statistically significant if $P<0.05$.

\section{Results}

\section{Distribution of Rab18 in adipose tissue}

Immunohistochemical examination of WAT sections or isolated mature adipocytes revealed that Rab18 immunoreactivity was present at the surface of the characteristically large unilocular LD (Fig. 1A and B). Rab18 immunoreactivity also showed a diffuse distribution within the thin layer of cytoplasm between the LD and the cell surface in isolated adipocytes (Fig. 1B).

Published by Bioscientifica Ltd. 
Immunoblotting confirmed the presence of Rab18 immunoreactivity in mature adipocytes isolated from visceral and subcutaneous WAT, which also showed a strong immunosignal for the adipocyte marker, adiponectin, but not for the leukocyte marker CD45 (Fig. 1C). Rab18 immunosignal was also noticeable in the SVF of subcutaneous and visceral fat, characterized by the expression of CD45 (Fig. 1C).

\section{Influence of age and gender on Rab18 expression}

In WAT from both male and female rats, Rab18 expression was undetectable at P15 but was clearly detectable at P45, where levels remained constant up to P90, with no apparent sex differences (Fig. 2).

\section{Effect of fasting on WAT Rab18 mRNA expression}

As shown in Fig. 3A, Rab18 transcripts in visceral WAT increased with fasting, in a time-dependent manner, reaching a maximal value after $48 \mathrm{~h}$ of fasting (13-fold increase compared with control animals). Rab18 expression levels in subcutaneous WAT also increased

A

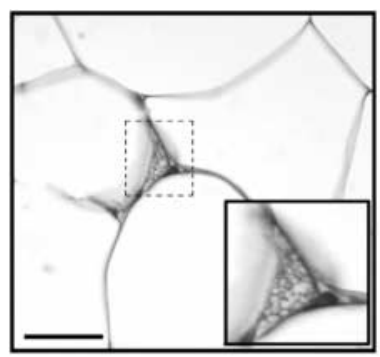

C

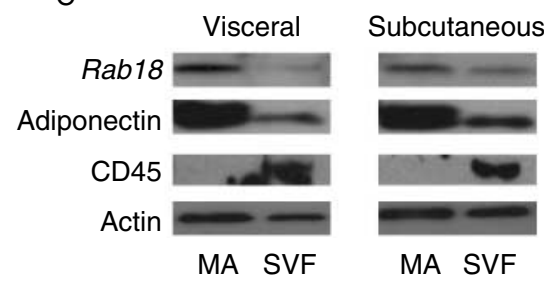

Figure 1

Distribution of Rab18 in rat WAT. Rab18 immunohistochemistry in paraffin sections from adult rat visceral (perigonal) adipose tissue (A) and in isolated mature adipocytes (B). Scale bars, $25 \mu \mathrm{m}$. (C) Immunoblot analysis of Rab18 in total adipose tissue (WAT) as well as in mature adipocytes (MA) and the SVF of visceral and subcutaneous fat. A single immunoreactive band of $23 \mathrm{kDa}$ corresponding to mouse Rab18 was found. Adiponectin and CD45 were employed as markers of mature adipocytes and SVF respectively.

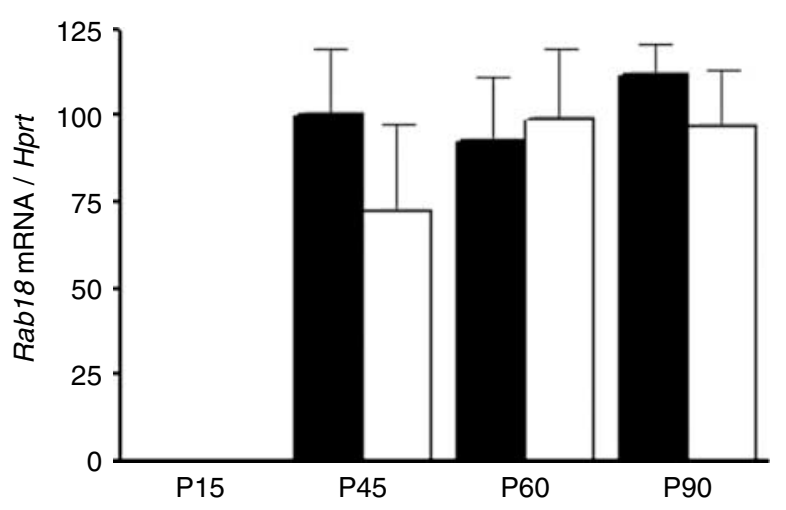

Figure 2

WAT Rab18 expression during rat postnatal development. WAT Rab18 expression was evaluated in both male (solid bars) and female rats (open bars) at postnatal (P) day 15, 45, 60, and 90 by quantitative RT-PCR. Rab18 expression levels were adjusted by the expression levels of the housekeeping gene, Hprt. Mean Rab18 mRNA levels were then expressed as a percentage of Rab18 mRNA levels in adipose tissue of male rats at P45 $(100 \%)$. Data represent the mean \pm s.E.M. ( $n=4-6$ animals per group). No statistical differences in Rab18 mRNA content were observed in relation to gender or age from P45 onward.

after $12 \mathrm{~h}$ of fasting (15-fold increased compared with ad libitum-fed mice). However, in contrast to that observed in visceral fat, Rab18 mRNA levels in subcutaneous WAT tended to return to fed levels with prolonged fasting ( 24 and 48 h; Fig. 3B). Similar results were observed when RAB18 protein content in samples from fasted mice was assessed by immunoblotting (Fig. 3C).

\section{Effects of diet-induced and genetic obesity on Rab18 expression}

Ten weeks of HFD increased visceral WAT Rab18 mRNA levels to sixfold that observed in LFD controls (Fig. 4A). Likewise, Rab18 mRNA levels in subcutaneous WAT were tenfold higher in mice fed HFD than in mice fed LFD (Fig. 4B). After 16 weeks of HFD, visceral and subcutaneous WAT Rab18 transcript levels remained elevated (Fig. 4C and D), although differences between HFD-fed and LFD-fed animals were less pronounced than in the 10-week group. Rab18 mRNA content in visceral and subcutaneous fat from obese, leptin-deficient mice (i.e. $o b / o b$ mice) was also dramatically elevated in both visceral (Fig. 4E) and subcutaneous (Fig. 4F) WAT, compared with lean controls (400- and 300-fold respectively). The differences in Rab18 mRNA levels in visceral WAT were largely matched by changes in protein expression; however, RAB18 protein levels in subcutaneous WAT did not differ between LFD and HFD groups (Fig. 4G).

Published by Bioscientifica Ltd 


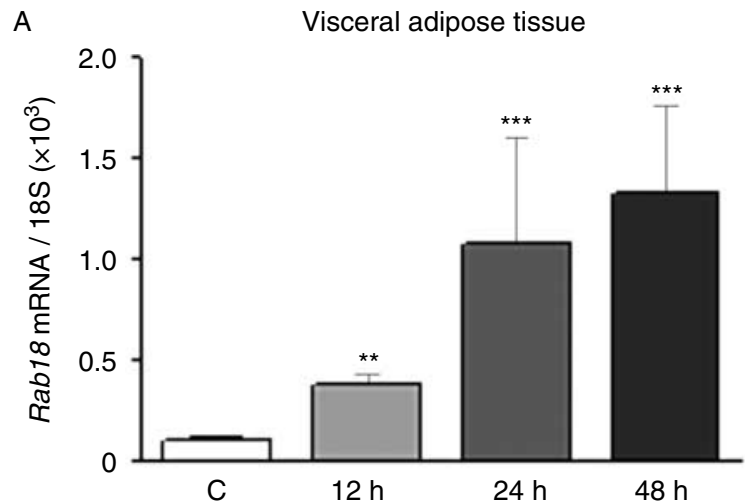

B

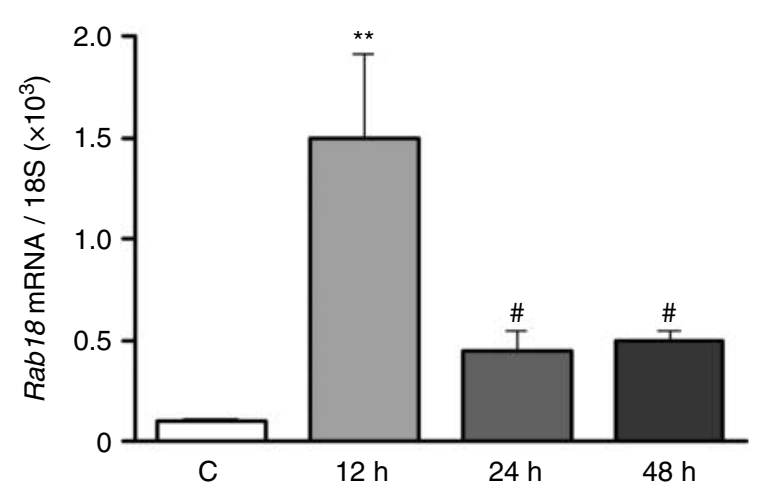

C

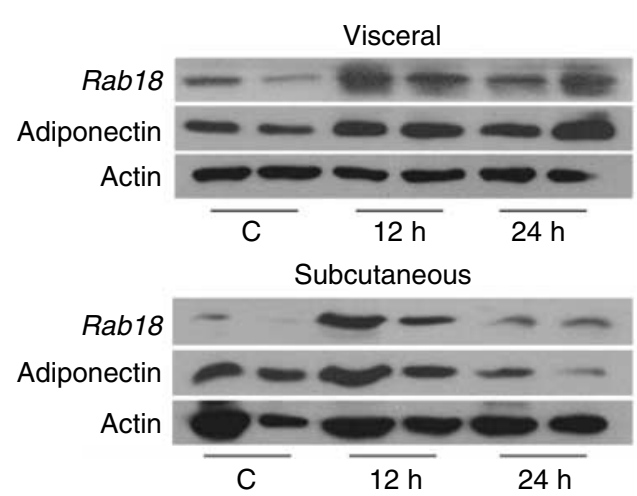

Figure 3

Effects of fasting on WAT Rab18 expression. Quantification of Rab18 mRNA levels in visceral (A) and subcutaneous (B) WAT from mice subjected to food deprivation for 12,24 , and $48 \mathrm{~h}$. Rab18 expression levels were adjusted by the expression levels of the housekeeping gene, 18s RNA. Mean Rab18 mRNA levels were then expressed as a percentage of Rab18 mRNA levels in control mice $(100 \%)$. Data represent the mean \pm s.E.M. $(n=3-6$ animals per group). $* * P<0.01$, and $* * * P<0.001$ vs corresponding controls; ${ }^{*} P<0.05$ vs 12-h fasting. (C) RAB 18 protein content in visceral and subcutaneous adipose tissue samples of control mice and mice fasted for 12 or $24 \mathrm{~h}$. Adiponectin and $\beta$-actin were also evaluated in each blot.
RAB18 protein content was higher in both visceral and subcutaneous adipose tissue of $o b / o b$ animals than in their corresponding control counterparts (Fig. 4H). As shown in Fig. $4 \mathrm{G}$ and $\mathrm{H}$, adiponectin protein expression in adipose tissue decreased in both diet-induced and genetic obesity, with the most pronounced differences observed in visceral WAT.

Similar to that found in $o b / o b$ mice, visceral WAT samples from NZO mice also showed increased levels of Rab18 expression compared with their corresponding lean control animals (14-fold higher; Fig. 5A), although differences were less pronounced than those observed in $o b / o b$ mice. Interestingly, similar to that observed in lean mice (Fig. 3A), 48-h fasting increased Rab18 mRNA content in visceral WAT of NZO mice (Fig. 5B).

\section{Hormonal regulation of WAT Rab18 gene expression}

Given the involvement of pituitary hormones, and those produced by other endocrine tissues controlled by this gland, in the regulation of adipocyte lipid metabolism (Schaffler et al. 2005, 2006), we explored the impact of disrupting pituitary hormone output on Rab18 mRNA levels in WAT. As illustrated in Fig. 6A, Rab18 expression was 1.9-fold higher in hypophysectomized rats than in sham-operated animals, thus indicating that pituitary hormones, either directly or via their actions on peripheral glands, could be involved in the regulation of Rab18 gene expression in WAT. To ascertain which pituitary hormone(s) are responsible for maintaining WAT Rab18 expression, Rab18 mRNA levels were measured in $\mathrm{GH}$ deficient (dwarf; Fig. 6B), gonadectomized (Fig. 6C and D), adrenalectomized (with and without dexamethasone treatment; Fig. 6E), and hyperthyroid rats (Fig. 6F) and found not to differ from their respective controls. However, of note, hypothyroidism increased WAT Rab18 mRNA (Fig. 6F) and protein (Fig. 6G) levels compared with euthyroid rats.

\section{Discussion}

In this study, we demonstrate that Rab18, which is associated with the surface of LDs in primary adipocytes, is regulated in WAT in an age- and depot-dependent manner, in relation to the energy status (i.e. fasting and diet-induced or genetic obesity), and thyroid function. These observations, mostly based on mRNA data, are in agreement with previous functional results supporting the participation of Rab18 in the regulation of lipid metabolism in adipose tissue (Pulido et al. 2011).

Published by Bioscientifica Ltd 
A

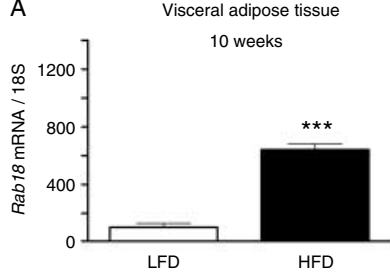

C

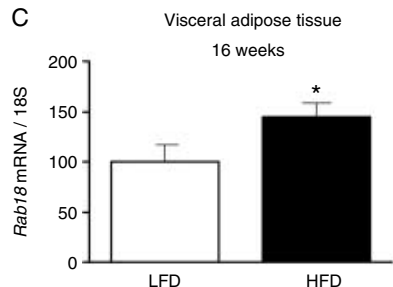

Visceral adipose tissue

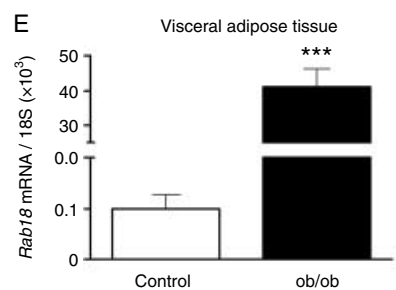

Subcutaneous adipose tissue

$G$

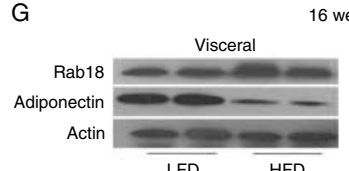

LFD
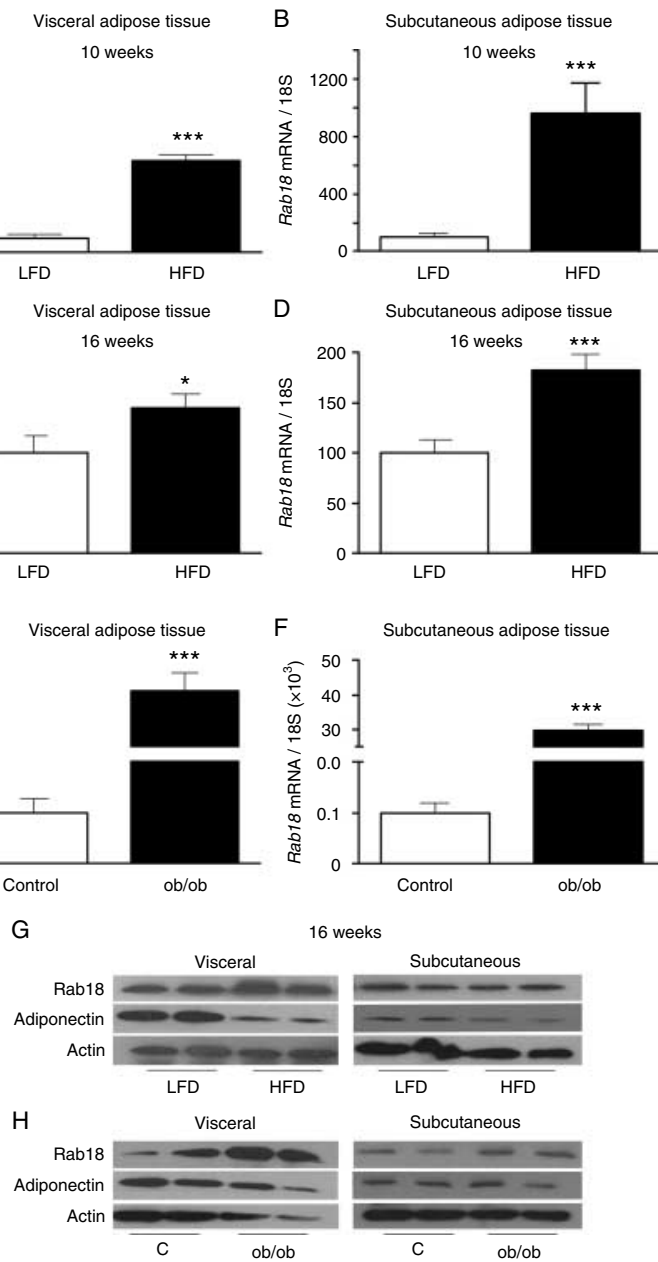

D
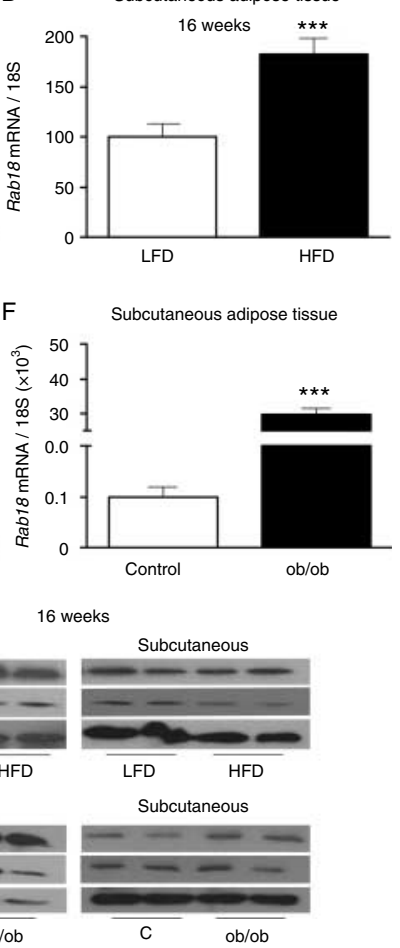

Figure 4

Effects of diet-induced and genetic obesity on WAT Rab18 expression. Rab18 mRNA levels were analyzed in visceral ( $A, C$ and $E$ ) and subcutaneous ( $B, D$ and F) WAT obtained from mice fed on a high- or a low-fat diet (HFD and LFD respectively) for 10 ( $A$ and $B$ ) or 16 ( $C$ and $D$ ) weeks and in chow-fed leptin-deficient ob/ob mice and their lean controls ( $E$ and F). Results are expressed as a percentage of Rab18 mRNA levels in animals fed LFD (A, B, C and D) or in lean control mice (E and F) (100\%). Data represent the mean \pm s.E.M. ( $n=4-6$ animals per group). $* P<0.05$ and $* * * P<0.001$ vs corresponding controls. Representative blots showing RAB 18 protein content in visceral and subcutaneous adipose tissue samples of LFD and HFD mice (G) and of control and ob/ob mice (H). Adiponectin and $\beta$-actin were also evaluated in each blot.

During postnatal development, Rab18 expression was undetectable in visceral WAT from P15 rats, thereby suggesting that this GTPase is not required for the initial expansion of adipose tissue, which occurs in early postnatal life (Gregoire et al. 1998). However, RAB18 expression exhibited a marked increase during puberty, reaching the highest levels at $\mathrm{P} 45$ and remaining elevated thereafter. This age-related increase in RAB18 expression coincides with the period of highest adipocyte

hypertrophy in rat WAT, which occurs between P40 and P80 and is characterized by an increase in the lipogenic activity and a decline in the lipolytic rate of adipocytes (Tsujikawa \& Kimura 1980, Herrera \& Amusquivar 2000). Accordingly, it has been reported that Rab18 mRNA expression and protein content increased in 3T3-L1 adipocytes as these cells accumulated lipids during differentiation (Pulido et al. 2011). This may account for the presence of Rab18 immunoreactivity in the SVF of both subcutaneous and visceral fat, as this component of WAT contains a population of preadipocytes (Frayn et al. 2003). Nevertheless, we cannot exclude the possibility that other cell types in the SVF can also contribute to the changes in Rab18 mRNA content observed in this study. It is notable that in spite of the sexual differences in the lipolytic and lipogenic rates of adipose tissue, which have been largely attributed to the influence of sex steroids (Shi \& Clegg 2009, Shi et al. 2009), no gender-related differences in Rab18 mRNA expression were observed at any of the ages tested, even in periods of increased sex steroids levels (i.e. puberty). In line with this, we observed that gonadectomy did not modify Rab18 transcript levels in WAT.

Our study also showed that fasting induced a strong, time-dependent increase in Rab18 gene expression in WAT, which supports the participation of this protein in the adaptive response of adipose tissue to maintain wholebody homeostasis. During fasting, increased concentrations of circulating catecholamines and glucocorticoids promote mobilization of lipid stores from adipose tissue (Langin 2006, Rose et al. 2010). Glucocorticoids do not appear to play a major role in the regulation of Rab18 expression in WAT as much as administration of dexamethasone to either adrenalectomized or sham-operated animals did not alter the expression levels of this GTPase. Additionally, exposure of 3T3-L1 adipocytes to dexamethasone had no effect on Rab18 mRNA levels (Pulido et al. 2011). On the other hand, the $\beta$-adrenergic agonist isoproterenol, besides increasing the association of this protein to the LD surface, enhanced Rab18 transcript and protein content in 3T3-L1 cells (Pulido et al. 2011). Taken together, these data suggest the involvement of Rab18 in $\beta$-adrenergic receptor-stimulated lipolysis during shortterm energy deficit. Our results on the distinct timecourse profile of Rab18 mRNA expression exhibited by subcutaneous and visceral fat in response to fasting also support this notion. To be more specific, whereas Rab18 mRNA content in visceral fat increased steadily over a 48-h fasting period, subcutaneous fat exhibited a sharp but transient increase in Rab18 mRNA levels in response

Published by Bioscientifica Ltd. 
A

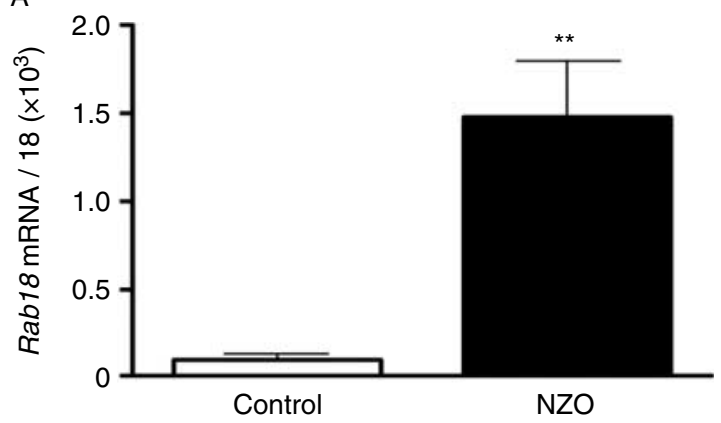

B

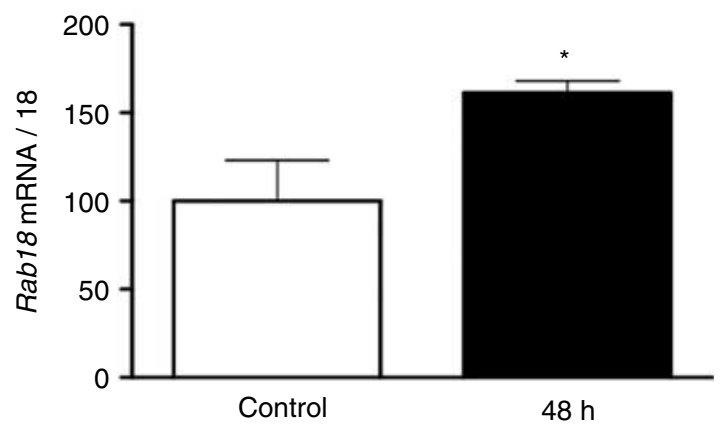

Figure 5

WAT Rab18 expression in NZO obese mice. (A) Rab18 mRNA levels were analyzed in visceral WAT of NZO mice and their corresponding controls. (B) NZO mice were subjected to food deprivation for $48 \mathrm{~h}$. Results are expressed as a percentage of Rab18 mRNA levels in control mice (100\%). Data represent the mean \pm s.E.M. ( $n=3-5$ animals per group). ${ }^{*} P<0.05$; $* \star P<0.01$ vs corresponding controls.

to food deprivation. Moreover, changes in RAB18 protein content in adipose tissue samples induced by fasting were similar to those observed for Rab18 mRNA. These observations are in accordance with the higher expression levels of $\beta$-adrenergic receptors and increased $\beta$-adrenergic stimulation of lipolysis exhibited by visceral, compared with subcutaneous, WAT (Hoffstedt et al. 1997, Umekawa et al. 1997, Portillo et al. 2000). Moreover, visceral fat is more responsive to fasting conditions than subcutaneous fat with regard to the induction of the lipolytic enzymes, hormone-sensitive lipase (HSL; Akesson et al. 2003), and adipose triglyceride lipase (ATGL; Palou et al. 2010). In this context, the results of the current study raise the possibility that Rab18 induction may help to sustain the higher lipolytic activity of visceral vs subcutaneous fat in response to energy deprivation.

Remarkably, we observed that Rab18 mRNA levels in WAT were strongly increased in obesity induced by HFD, hyperphagia due to leptin deficiency ( $o b / o b$ mice), or to polygenic alterations (New Zealand mice). A similar trend was observed for RAB18 protein expression in WAT from HFD mice and $o b / o b$ mice. In agreement with these findings, we have recently shown that obese humans also exhibit enhanced Rab18 expression levels in both visceral and subcutaneous fat (Pulido et al. 2011). Together, these data suggest that Rab18 may be involved in the metabolic changes occurring in fat under conditions of energy excess. In particular, HFD-induced obesity is characterized by increased basal catecholamine-induced lipolysis (Jocken \& Blaak 2008, Gaidhu et al. 2010). Likewise, adipose tissue of $o b / o b$ mice exhibits higher rates of net lipolysis than their lean controls (Turner et al. 2007). Intriguingly, although gene
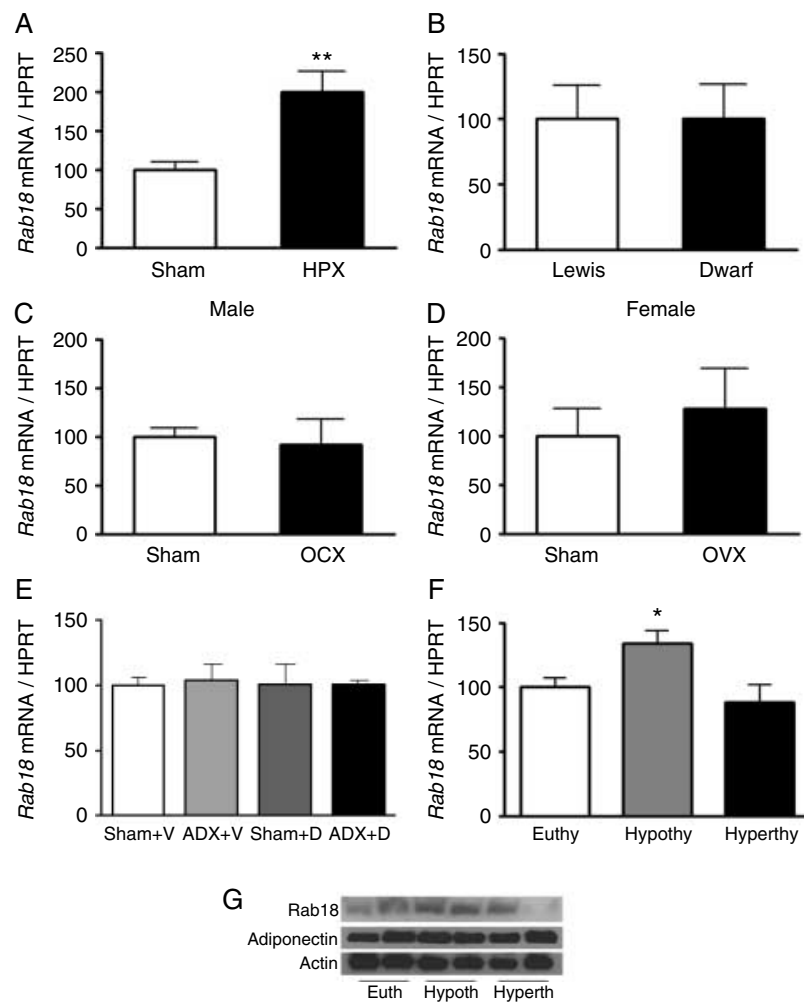

\section{Figure 6}

Hormonal regulation of WAT Rab18 gene expression. The contribution of pituitary-regulated endocrine axes to the control of WAT Rab18 mRNA expression was studied in hypophysectomized (HPX) (A), GH-deficient (Dwarf) (B), orchidectomized (OCX) (C), and ovariectomized (OVX) (D) rats, as well as in adrenalectomized (ADX) animals with $(A D X+D)$ or without dexamethasone replacement (E), and in eu-, hypo-, and hyperthyroid rats (F). Hormonal deficiency was induced in each case as described in Materials and methods section. Results are expressed as a percentage of Rab18 mRNA levels in each respective control (100\%). Values are the mean \pm s.E.M. ( $n=3-6$ animals per group). ${ }^{*} P<0.05$ and $* * P<0.01$ vs euthyroid and sham-operated rats respectively. (G) Representative blots showing RAB18, adiponectin, and $\beta$-actin protein contents in adipose tissue samples of control, hypo-, and hyperthyroid rats. 
expression studies have commonly reported reduced or normal expression levels of lipogenic genes in $o b / o b$ mice (Nadler et al. 2000), measurement of triacylglyceride synthesis and de novo lipogenesis has revealed that adipose tissue capacity for lipid anabolism and storage is markedly increased in these animals (Turner et al. 2007). Notably, overexpression of Rab18 stimulates both lipolytic and lipogenic rates in 3T3-L1 adipocytes (Pulido et al. 2011). According to these data, it is tempting to propose that this protein could participate in the regulation of lipid mobilization from (i.e. lipolysis) and to (i.e. lipogenesis) LDs in response to increased adiposity.

Besides the marked effects on Rab18 mRNA levels triggered by changes in the energy status, disruption of pituitary signaling also altered the expression of this GTPase in WAT. Specifically, WAT Rab18 mRNA levels increased significantly in hypophysectomized rats, indicating that pituitary hormones, either directly or through their action on target glands, regulate the expression of this GTPase. However, most of the experimental procedures aimed at disrupting different pituitary-related endocrine axes were ineffective at altering Rab18 expression, with the exception of hypothyroidism. Specifically, hypothyroidism upregulated Rab18 mRNA expression, as hypophysectomy did, and also increased WAT RAB18 protein content. Interestingly, both hypophysectomy and hypothyroidism have been shown to decrease basal and catecholamine-stimulated lipolysis (Malbon et al. 1978, Mills et al. 1986, Yang et al. 1996), where lipogenesis is unchanged or increased (Correze et al. 1982, Baht \& Saggerson 1988, Hausman et al. 1999). In all, our data suggest that hypophysectomy-induced effects on Rab18 mRNA expression may be mediated by the decrease in circulating thyroid hormones resulting from the lack of pituitary TSH. Nonetheless, we cannot exclude the possibility that other pituitary hormones (or lack thereof) not investigated in this study and known to act on adipose tissue, such as PRL (Brandebourg et al. 2007), might also be responsible, at least in part, for the effects observed in hypophysectomized animals.

From the findings reported herein, it is worthy to highlight that Rab18 expression is upregulated in rodent WAT from both visceral and subcutaneous depots in response to different metabolic situations, which might represent an adaptive response to overcome the alterations in lipid metabolism occurring under such conditions. Thus, Rab18 is induced in states of augmented lipogenesis and decreased lipolysis, as occurs during postnatal development, when the pituitary/thyroid axis is disrupted, in states of increased lipolytic activity mediated by sympathetic signaling triggered by fasting, and in states of increased lipogenic and lipolytic activities as a result of obesity. These observations are largely in accordance with our previous functional data in 3T3-L1 adipocytes demonstrating the participation of Rab18 as a common intracellular mediator of lipolysis and lipogenesis (Pulido et al. 2011). Together, these data suggest the involvement of Rab18 in the regulation of lipid metabolism in adipose tissue under physiological and pathological conditions and provide further support to the idea that this may occur by controlling both the lipolytic and the lipogenic activities of adipocytes.

\section{Declaration of interest}

The authors declare that there is no conflict of interest that could influence the impartiality of the research reported.

\section{Funding}

This work was supported by Ministerio de Economia y Competitividad (MINECO)/FEDER (BFU2007-60180 and BFU2010-17116 to M M M, Al HF2007-0002 to R V-M, FPU AP2005-3348 to M R P, MAEC-AECID to F A, and RYC-2007-00186 to R M L), Junta de Andalucía/FEDER (CTS-03039 and CTS-6606 to M M M), National Institute of Diabetes and Digestive and Kidney Diseases Grant 30677 (to R D K) and CIBER Obesidad y Nutrición (CIBERobn), Instituto de Salud Carlos III, Spain.

\section{Acknowledgements}

The authors are indebted to M Ortega-Bellido and L Molero for technical assistance.

\section{References}

Akesson L, Ahren B, Manganiello VC, Holst LS, Edgren G \& Degerman E 2003 Dual effects of pituitary adenylate cyclase-activating polypeptide and isoproterenol on lipid metabolism and signaling in primary rat adipocytes. Endocrinology 144 5293-5299. (doi:10.1210/en.2003-0364)

Archanco M, Gomez-Ambrosi J, Tena-Sempere M, Fruhbeck G \& Burrell MA 2007 Expression of leptin and adiponectin in the rat oviduct. Journal of Histochemistry and Cytochemistry 55 1027-1037. (doi:10.1369/jhc. 6A7128.2007)

Baht HS \& Saggerson ED 1988 Comparison of triacylglycerol synthesis in rat brown and white adipocytes. Effects of hypothyroidism and streptozotocin-diabetes on enzyme activities and metabolic fluxes. Biochemical Journal 250 325-333.

Barreiro ML, Gaytan F, Caminos JE, Pinilla L, Casanueva FF, Aguilar E, Dieguez C \& Tena-Sempere M 2002 Cellular location and hormonal regulation of ghrelin expression in rat testis. Biology of Reproduction $\mathbf{6 7}$ 1768-1776. (doi:10.1095/biolreprod.102.006965)

Brandebourg TD, Bown JL \& Ben-Jonathan N 2007 Prolactin upregulates its receptors and inhibits lipolysis and leptin release in male rat adipose tissue. Biochemical and Biophysical Research Communications $\mathbf{3 5 7}$ 408-413. (doi:10.1016/j.bbrc.2007.03.168)

Brasaemle DL 2007 Thematic review series: adipocyte biology. The perilipin family of structural lipid droplet proteins: stabilization of lipid droplets

Published by Bioscientifica Ltd. 
and control of lipolysis. Journal of Lipid Research $\mathbf{4 8} 2547-2559$. (doi:10.1194/jlr.R700014-JLR200)

Brasaemle DL, Dolios G, Shapiro L \& Wang R 2004 Proteomic analysis of proteins associated with lipid droplets of basal and lipolytically stimulated 3T3-L1 adipocytes. Journal of Biological Chemistry 279 46835-46842. (doi:10.1074/jbc.M409340200)

Brown DA 2001 Lipid droplets: proteins floating on a pool of fat. Current Biology 11 R446-R449. (doi:10.1016/S0960-9822(01)00257-3)

Charlton HM, Clark RG, Robinson ICAF, Porter-Gof AE, Cox BS, Bugnon C \& Bloch BS 1988 Growth hormone-deficient dwarfism: a new mutation. Journal of Endocrinology 119 51-58. (doi:10.1677/joe.0.1190051)

Correze C, Berriche S, Tamayo L \& Nunez J 1982 Effect of thyroid hormones and cyclic AMP on some lipogenic enzymes of the fat cell. European Journal of Biochemistry 122 387-392. (doi:10.1111/j.1432-1033.1982. tb05893.x)

Ducharme NA \& Bickel PE 2008 Lipid droplets in lipogenesis and lipolysis. Endocrinology 149 942-949. (doi:10.1210/en.2007-1713)

Frayn KN, Karpe F, Fielding BA, Macdonald IA \& Coppack SW 2003 Integrative physiology of human adipose tissue. International Journal of Obesity and Related Metabolic Disorders 27 875-888. (doi:10.1038/sj.ijo. 0802326)

Gaidhu MP, Anthony NM, Patel P, Hawke TJ \& Ceddia RB 2010 Dysregulation of lipolysis and lipid metabolism in visceral and subcutaneous adipocytes by high-fat diet: role of ATGL, HSL, and AMPK. American Journal of Physiology. Cell Physiology 298 C961-C971. (doi:10.1152/ajpcell.00547.2009)

Gong J, Sun Z \& Li P 2009 CIDE proteins and metabolic disorders. Current Opinion in Lipidology 20 121-126. (doi:10.1097/MOL. 0b013e328328d0bb)

Goodman JM 2008 The gregarious lipid droplet. Journal of Biological Chemistry 283 28005-28009. (doi:10.1074/jbc.R800042200)

Gregoire FM, Smas CM \& Sul HS 1998 Understanding adipocyte differentiation. Physiological Reviews 78 783-809.

Guo Y, Walther TC, Rao M, Stuurman N, Goshima G, Terayama K, Wong JS, Vale RD, Walter P \& Farese RV 2008 Functional genomic screen reveals genes involved in lipid-droplet formation and utilization. Nature $\mathbf{4 5 3}$ 657-661. (doi:10.1038/nature06928)

Guo Y, Cordes KR, Farese RV Jr \& Walther TC 2009 Lipid droplets at a glance. Journal of Cell Science 122 749-752. (doi:10.1242/jcs.037630)

Hausman DB, Hausman GJ \& Martin RJ 1999 Endocrine regulation of fetal adipose tissue metabolism in the pig: interaction of porcine growth hormone and thyroxine. Obesity Research 7 76-82. (doi:10.1002/j.15508528.1999.tb00393.x)

Herrera E \& Amusquivar E 2000 Lipid metabolism in the fetus and the newborn. Diabetes/Metabolism Research and Reviews 16 202-210. (doi:10.1002/1520-7560(200005/06)16:3<202::AID-DMRR116>3.0. $\mathrm{CO} ; 2-)$

Hoffstedt J, Arner P, Hellers G \& Lonnqvist F 1997 Variation in adrenergic regulation of lipolysis between omental and subcutaneous adipocytes from obese and non-obese men. Journal of Lipid Research 38 795-804.

Hommel A, Hesse D, Volker W, Jaschke A, Moser M, Engel T, Bluher M, Zahn C, Chadt A, Ruschke K et al. 2010 The ARF-like GTPase ARFRP1 is essential for lipid droplet growth and is involved in the regulation of lipolysis. Molecular and Cellular Biology 30 1231-1242. (doi:10.1128/ MCB.01269-09)

Jocken JW \& Blaak EE 2008 Catecholamine-induced lipolysis in adipose tissue and skeletal muscle in obesity. Physiology \& Behavior 94 219-230. (doi:10.1016/j.physbeh.2008.01.002)

Kershaw EE \& Flier JS 2004 Adipose tissue as an endocrine organ. Journal of Clinical Endocrinology and Metabolism 89 2548-2556. (doi:10.1210/jc. 2004-0395)

Kolditz CI \& Langin D 2010 Adipose tissue lipolysis. Current Opinion in Clinical Nutrition and Metabolic Care 13 377-381. (doi:10.1097/MCO. 0b013e32833bed6a)
Kuerschner L, Moessinger C \& Thiele C 2008 Imaging of lipid biosynthesis: how a neutral lipid enters lipid droplets. Traffic 9 338-352. (doi:10.1111/j.1600-0854.2007.00689.x)

Langin D 2006 Adipose tissue lipolysis as a metabolic pathway to define pharmacological strategies against obesity and the metabolic syndrome. Pharmacological Research 53 482-491. (doi:10.1016/j.phrs.2006. 03.009)

Liu P, Bartz R, Zehmer JK, Ying YS, Zhu M, Serrero G \& Anderson RG 2007 Rab-regulated interaction of early endosomes with lipid droplets. Biochimica et Biophysica Acta 1773 784-793. (doi:10.1016/j.bbamcr. 2007.02.004)

Lopez M, Seoane L, Senaris RM \& Dieguez C 2001 Prepro-orexin mRNA levels in the rat hypothalamus, and orexin receptors mRNA levels in the rat hypothalamus and adrenal gland are not influenced by the thyroid status. Neuroscience Letters 300 171-175. (doi:10.1016/S03043940(01)01569-5)

Luque R \& Kineman R 2006 Impact of obesity on the growth hormone axis: evidence for a direct inhibitory effect of hyperinsulinemia on pituitary function. Endocrinology 147 2754-2763. (doi:10.1210/en.2005-1549)

Malbon CC, Moreno FJ, Cabelli RJ \& Fain JN 1978 Fat cell adenylate cyclase and $\beta$-adrenergic receptors in altered thyroid states. Journal of Biological Chemistry 253 671-678.

Martin S, Driessen K, Nixon SJ, Zerial M \& Parton RG 2005 Regulated localization of Rab18 to lipid droplets: effects of lipolytic stimulation and inhibition of lipid droplet catabolism. Journal of Biological Chemistry 280 42325-42335. (doi:10.1074/jbc.M506651200)

Mills I, Garcia-Sainz JA \& Fain JN 1986 Pertussis toxin effects on adenylate cyclase activity, cyclic AMP accumulation and lipolysis in adipocytes from hypothyroid, euthyroid and hyperthyroid rats. Biochimica et Biophysica Acta 876 619-630. (doi:10.1016/0005-2760(86)90051-2)

Miyoshi H, Perfield JW II, Obin MS \& Greenberg AS 2008 Adipose triglyceride lipase regulates basal lipolysis and lipid droplet size in adipocytes. Journal of Cellular Biochemistry 105 1430-1436. (doi:10.1002/jcb.21964)

Murphy DJ 2001 The biogenesis and functions of lipid bodies in animals, plants and microorganisms. Progress in Lipid Research 40 325-438. (doi:10.1016/S0163-7827(01)00013-3)

Murphy S, Martin S \& Parton RG 2009 Lipid droplet-organelle interactions; sharing the fats. Biochimica et Biophysica Acta 1791 441-447. (doi:10.1016/j.bbalip.2008.07.004)

Nadler ST, Stoehr JP, Schueler KL, Tanimoto G, Yandell BS \& Attie AD 2000 The expression of adipogenic genes is decreased in obesity and diabetes mellitus. PNAS 97 11371-11376. (doi:10.1073/pnas.97.21.11371)

Nogueiras R, Gualillo O, Caminos JE, Casanueva FF \& Dieguez C 2003 Regulation of resistin by gonadal, thyroid hormone, and nutritional status. Obesity Research 11 408-414. (doi:10.1038/oby.2003.55)

Ozeki S, Cheng J, Tauchi-Sato K, Hatano N, Taniguchi H \& Fujimoto T 2005 Rab18 localizes to lipid droplets and induces their close apposition to the endoplasmic reticulum-derived membrane. Journal of Cell Science 118 2601-2611. (doi:10.1242/jcs.02401)

Palou M, Sanchez J, Priego T, Rodriguez AM, Pico C \& Palou A 2010 Regional differences in the expression of genes involved in lipid metabolism in adipose tissue in response to short- and medium-term fasting and refeeding. Journal of Nutritional Biochemistry 21 23-33. (doi:10.1016/j.jnutbio.2008.10.001)

Peinado JR, Jimenez-Gomez Y, Pulido MR, Ortega-Bellido M, Diaz-Lopez C, Padillo FJ, Lopez-Miranda J, Vazquez-Martinez R \& Malagon MM 2010 The stromal-vascular fraction of adipose tissue contributes to major differences between subcutaneous and visceral fat depots. Proteomics 10 3356-3366. (doi:10.1002/pmic.201000350)

Portillo MP, Villaro JM, Torres MI \& Macarulla MT 2000 In vivo lipolysis in adipose tissue from two anatomical locations measured by microdialysis. Life Sciences 67 437-445. (doi:10.1016/S0024-3205(00) 00642-1)

Pulido MR, Diaz-Ruiz A, Jimenez-Gomez Y, Garcia-Navarro S, Gracia-Navarro F, Tinahones F, Lopez-Miranda J, Fruhbeck G, 
Vazquez-Martinez R \& Malagon MM 2011 Rab18 dynamics in adipocytes in relation to lipogenesis, lipolysis and obesity. PLOS ONE 6 e22931. (doi:10.1371/journal.pone.0022931)

Rose AJ, Vegiopoulos A \& Herzig S 2010 Role of glucocorticoids and the glucocorticoid receptor in metabolism: insights from genetic manipulations. Journal of Steroid Biochemistry and Molecular Biology 122 10-20. (doi:10.1016/j.jsbmb.2010.02.010)

Schaffler A, Binart N, Scholmerich J \& Büchler C 2005 Hypothesis paper brain talks with fat - evidence for a hypothalamic-pituitary-adipose axis? Neuropeptides 39 363-367. (doi:10.1016/j.npep.2005.06.003)

Schaffler A, Scholmerich J \& Buechler C 2006 The role of 'adipotropins' and the clinical importance of a potential hypothalamic-pituitary-adipose axis. Nature Clinical Practice. Endocrinology \& Metabolism 2 374-383. (doi:10.1038/ncpendmet0197)

Shi H \& Clegg DJ 2009 Sex differences in the regulation of body weight. Physiology \& Behavior 97 199-204. (doi:10.1016/j.physbeh.2009.02.017)

Shi H, Seeley RJ \& Clegg DJ 2009 Sexual differences in the control of energy homeostasis. Frontiers in Neuroendocrinology 30 396-404. (doi:10.1016/j. yfrne.2009.03.004)

Tsujikawa M \& Kimura S 1980 Changes in lipid synthesis in rat adipose tissue during development. Journal of Nutritional Science and Vitaminology 26 367-374. (doi:10.3177/jnsv.26.367)

Turner SM, Roy S, Sul HS, Neese RA, Murphy EJ, Samandi W, Roohk DJ \& Hellerstein MK 2007 Dissociation between adipose tissue fluxes and lipogenic gene expression in ob/ob mice. American Journal of Physiology. Endocrinology and Metabolism 292 E1101-E1109. (doi:10.1152/ajpendo. 00309.2005)

Umekawa T, Yoshida T, Sakane N \& Kondo M 1997 Effect of CL316,243, a highly specific $\beta(3)$-adrenoceptor agonist, on lipolysis of epididymal, mesenteric and subcutaneous adipocytes in rats. Endocrine Journal $\mathbf{4 4}$ 181-185. (doi:10.1507/endocrj.44.181)

Varela L, Martínez-Sánchez N, Gallego R, Vázquez MJ, Roa J, Gándara M, Schoenmakers E, Nogueiras R, Chatterjee K, Tena-Sempere M et al. 2012 Hypothalamic mTOR pathway mediates thyroid hormone-induced hyperphagia in hyperthyroidism. Journal of Pathology 227 209-222. (doi:10.1002/path.3984)

Watt MJ \& Spriet LL 2010 Triacylglycerol lipases and metabolic control: implications for health and disease. American Journal of Physiology. Endocrinology and Metabolism 299 E162-E168.

Wolins NE, Brasaemle DL \& Bickel PE 2006 A proposed model of fat packaging by exchangeable lipid droplet proteins. FEBS Letters $\mathbf{5 8 0}$ 5484-5491. (doi:10.1016/j.febslet.2006.08.040)

Yang S, Bjorntorp P, Liu X \& Eden S 1996 Growth hormone treatment of hypophysectomized rats increases catecholamine-induced lipolysis and the number of $\beta$-adrenergic receptors in adipocytes: no differences in the effects of growth hormone on different fat depots. Obesity Research 4 471-478. (doi:10.1002/j.1550-8528.1996.tb00256.x)

Received in final form 19 October 2012

Accepted 22 October 2012

Accepted Preprint published online 22 October 2012
C 2013 Society for Endocrinology Printed in Great Britain
Published by Bioscientifica Ltd. 